\title{
Synthetic Pyrethroids: Toxicity and Biodegradation
}

\author{
A.J. Thathe yus ${ }^{1, *}$, A.Deborah Gnana Selvam ${ }^{2}$ \\ ${ }^{1}$ Postgraduate and Research Department of Zoology, The American College, Madurai \\ ${ }^{2}$ Postgraduate Department of Immunology and Microbiology, The American College, Madurai \\ *Corresponding author: jthatheyus@y ahoo.co.in \\ Received January 09, 2013; Revised Month 21, 2013; Accepted May 22, 2013
}

\begin{abstract}
Synthetic pyrethroids are pesticides derived from naturally occurring pyrethrins, taken from pyrethrum of dried Chrysanthemum flowers. They are chemically designed to be more toxic with lower break down times and are formulated with synergists increasing potency and compromising the body's ability to detoxify the pesticide. Though claimed to be selectively toxic to insects, synthetic pyrethroids are extremely to xic to aquatic organisms, including fish in concentrations similar to those used for controlling mosquito, black fly and tsetse fly larvae, which are the actual targets of pyrethroids. Many pyrethroids have been linked to the disruption of the endocrine system, reproduction and sexual development, interference with the immune system and the induction of breast cancer. The widespread use of pyrethroids is a major problem as they pollute the agricultural lands and water resources and affect non-target organisms and humans. Recent studies show that some microbes are able to degrade synthetic pyrethroids by esterase production and this application is proposed as an inexpensive and simple method. In the present work, the aspects related to the toxicity and biodegradation of synthetic pyrethroids are discussed.
\end{abstract}

Keywords: synthetic pyrethroids, toxicity, biodegradation, microbes

\section{Introduction}

Contamination of the environment by chemicals is a serious and insidious side effect of human population explosion and technological advancement. Widespread uses of pesticides have not occurred until the $20^{\text {th }}$ century, though chemicals were employeded much earlier to control insects, fungi and weeds. With the reduction in the use of organochlorine pesticides in the late 1960s, organophosphorous compounds then carbamates and finally synthetic pyrethroids came in to the market. These compounds though short lived than organochlorines and do not accumulate, have resulted in increased mortality of fish and wildlife [1].

Pyrethrum, a natural extract of the flowers of the plants, Chrysanthemum cinerariaefolium and Chrysanthemum cineum, has been used as a natural insecticide for a long period of time. Initially the extracts of pyrethru m and later, the specific synthetic chemical analogs have been produced. The six active insecticidal compounds of pyrethrum are popularly known as pyrethrins. Synthetic pyrethroids (SPs) are synthetic analogs and derivatives of the original pyrethrins and include a variety group of about 1,000 insecticides. Though they are analogs of pyrethrins, their production has involved extensive chemical modifications which make them highly toxic and less degradable in the environment. The pyrethroids are grouped into two classes namely Type I and Type II, based on the toxicological and physical properties. Type I pyrethroids are derivatives of pyrethrin that do not have a cyano group and elicit tumors and type II pyrethroids have cyoano group and cause chloreoathetosis and salivation
(Table 1). Due to complex chemical structure, the pyrethroids are composed of two, four or eight isomers, and their commercially products may contain a mixture of these various isomers. The production of individual pyrethroids with varying is omeric ratios may be the reas on for the variations in the toxicities of the same compound. For increasing the efficiency of the insecticides, the pyrethroids are formu lated with compounds like piperonyl butoxide, piperonyl sulfoxide and sesamex, which act as synergists. Formulated commercial pyrethroids have a high percentage of other inert ingredients, which are highly toxic [2].

Table 1. Types of Synthetic Py reth roids

\begin{tabular}{|c|c|}
\hline Type I Pyrethroids & Type IIPyrethroids \\
\hline & Cyfluthrin \\
Allethrin & Cyhalothrin \\
Bifenthrin & Cypermethrin \\
Permethrin & Deltamethrin \\
Phenothrin & Fenvalerate \\
Resmethrin & Fenpropathrin \\
Tefluthrin & Flucythrinate \\
Teramethrin & Flumethrin \\
& Fluvalinate \\
& Tralomethrin \\
\hline
\end{tabular}

Gan et al. [3] have reported the enrichment of bifenthrin and permethrin during transport resulting in higher levels in the sediment downstream from the source. Agrochemical runoff is of much concern as it affects surface water quality and results in wide-spectrum aquatic toxicity.

In California alone, 360 metric tones of pyrethroids are used and the residues of the compounds are prevalent in agriculture affected aquatic systems [4]. Rain water residue analysis in Hisar, India has shown the occurrence of synthetic pyrethroids ranging from $0.100-1.000 \mu \mathrm{g} / \mathrm{l}$. Among the SPs detected, cypermethrin was found to be 
present in large quantities $(1 \mu \mathrm{g} / \mathrm{l})$. Presence of residues of these pesticides in rain water is fully justified as the vapors of these compounds come along with water [5]. These reports underlie the reality of pollution caused by pyrethroids and the need to reduce them.

\section{Uses}

Pyrethroids are broad spectrum insecticides, effective against a wide range of insect pests of the orders Coleoptera, Diptera, Hemiptera (Homoptera and Heteroptera), Hymenoptera, Lepidoptera, Orthoptera and Thysanoptera. Prior to harvest, they are sprayed over edible products to control pests and are also used as household insecticides and grain protectants. They are employed in animal houses, fields, green houses and extensively used in veterinary medicine [2] (Table 2). The efficacy of the pyrethroids and their selectivity between insect species depends on factors like shape, key structural features like ester or non-ester, specific chirality and cis or trans stereochemistry across the cyclopropane ring, physical properties (e.g. volatile compounds are good against flying insect pests) and chemical properties (e.g. polar compounds better for knockdown and high lipophilicity which result in reduced fish toxicity while fluorinated compounds have high miticidal activity) [6].

\begin{tabular}{|c|c|c|c|}
\hline Pyrethroid & Insects & Crops & $\begin{array}{l}\text { Other locations and } \\
\text { applications }\end{array}$ \\
\hline Allethrin & Flies, mosquitoes, ants & N/A & $\begin{array}{l}\text { Residential, public } \\
\text { health, animal houses, } \\
\text { topical application in pet } \\
\text { sprays and shampoos }\end{array}$ \\
\hline Bifenthrin & $\begin{array}{l}\text { Beetles, weevil, houseflies, } \\
\text { mosquit oes, lice, bedbugs, aphids, } \\
\text { moths, cockroaches, locust }\end{array}$ & $\begin{array}{l}\text { Alfalfa hay, beans, cant aloupes, cereals, corn, cotton, } \\
\text { field and grass seed, hops, melons, oilseed rape, pot atoes, } \\
\text { peas, raspberries, watermelons, squash }\end{array}$ & N/A \\
\hline Bioresmethrin & $\begin{array}{c}\text { Houseflies, mosquit oes, } \\
\text { cockroaches }\end{array}$ & N/A & $\begin{array}{c}\text { Household, public } \\
\text { health, animal houses }\end{array}$ \\
\hline Cyfluthrin & $\begin{array}{l}\text { Aphids, cabbage stem flea beetle, } \\
\text { cockroaches, houseflies, } \\
\text { mosquitoes, rape winter stem weevil }\end{array}$ & $\begin{array}{l}\text { Alfalfa, cereals, cotton, citrus, deciduous fruit, ground } \\
\text { nuts, maize, oilseed rape, pears, pot atoes, rice, sugar } \\
\text { beet, sugarcane, tobacco, vegetables. }\end{array}$ & Green houses \\
\hline Cyhalothrin & $\begin{array}{l}\text { Bedbugs, beetles, houseflies, ked, } \\
\text { lice, mosquitoes, moths, weevils }\end{array}$ & N/A & $\begin{array}{l}\text { Public health, animal } \\
\text { houses, inert surfaces }\end{array}$ \\
\hline Cypermethrin & $\begin{array}{l}\text { Cockroaches, flies, mosquitoes, } \\
\text { moths }\end{array}$ & $\begin{array}{l}\text { Cotton, lettuce, onions, pears, peaches, pecans, sugar } \\
\text { beets }\end{array}$ & $\begin{array}{c}\text { Residential and } \\
\text { commercial buildings, } \\
\text { animals houses }\end{array}$ \\
\hline Deltamethrin & $\begin{array}{l}\text { Aphids, beetles, bollworm, bud- } \\
\text { worm, caterpillars cicadas, coding } \\
\text { moths, totrix moths, weevils, } \\
\text { whitefly, winter moths }\end{array}$ & $\begin{array}{l}\text { Alfalfa, beet, cereals, coffee, cotton, figs, fruits, hops, } \\
\text { maize, oilseed rape, olives, oil palms, potat oes, rice, } \\
\text { soybeans, sunflowers, tea, tobacco, vegetables. }\end{array}$ & $\begin{array}{l}\text { Forests, households, } \\
\text { animal houses, stored } \\
\text { products }\end{array}$ \\
\hline Esfenvalerate & Beetles, moths & $\begin{array}{l}\text { Cabbage, corn, cotton, fruit trees, grains, groundnuts, } \\
\text { maize, pecan, potat oes, sorghum, soybeans, sugar cane, } \\
\text { sunflowers, sweet corn, tomatoes, veget ables, wheat }\end{array}$ & $\begin{array}{l}\text { Ornamentals, non crop } \\
\text { land. }\end{array}$ \\
\hline Fenvalerate & $\begin{array}{l}\text { Beet les, cockroaches, flies, locusts, } \\
\text { mosquit oes, moths }\end{array}$ & $\begin{array}{l}\text { Alfalfa hay, apples, beet, cereals, cotton, corn, cucurbita, } \\
\text { fruit, green beans, groundnuts, hops, maize, nuts, oilseed } \\
\text { rape, olives, potatoes, sorghum, soybeans, squash, } \\
\text { sugarcane, sunflower, veget ables, vines, tobacco. }\end{array}$ & $\begin{array}{l}\text { Ornamentals, forestry, } \\
\text { non-crop land. }\end{array}$ \\
\hline Fluvalinate & $\begin{array}{l}\text { Aphids, leafhoppers, moths, spider } \\
\text { mites, thrips, white-flies. }\end{array}$ & $\begin{array}{c}\text { Apples, cereals, cotton, pears, peaches, tobacco, } \\
\text { vegetables, vines }\end{array}$ & $\begin{array}{l}\text { Out door and indoor } \\
\text { ornamentals, turf. }\end{array}$ \\
\hline Permethrin & $\begin{array}{l}\text { Ants, beetle, bollworm, bud-worm, } \\
\text { fleas, flies, lice, moths, mosquitoes, } \\
\text { termites, weevils. }\end{array}$ & $\begin{array}{l}\text { Alfalfa hay, corn, cotton, grains, lettuce, onion, peaches, } \\
\text { potat oes, sweet corn, tomatoes, wheat. }\end{array}$ & $\begin{array}{l}\text { Home gardens, green } \\
\text { houses, pet sprays and } \\
\text { shampoos. }\end{array}$ \\
\hline
\end{tabular}

\section{Toxicity of Synthetic Pyrethroids}

\subsection{Acute Toxicity to Mammals}

Pyrethroids in general are less acutely toxic than the organochlorine, organophosphate and carbamate pesticides with the exeption of esfenvalerate, delta methrin, bifenthrin, tefluthrin, flucythrinate, cyhalothrin and fenpropathrin which show the highest acute oral to xicities. Acute and sub-acute studies have shown the main effects of pyrethroids as neurotoxicity at high doses and liver hypertrophy which are reversible if death does not occur. Many pyrethroids are mildly to severely irritating to the skin and eyes and some cause facial skin sensitization.

\subsection{Chronic and Sub-Chronic Toxicity}

Signs of acute toxicity in mammals are the most notable. Other effects include reduction in growth rate, liver enlargement, and an increase in the activity of some enzymes in the liver. Suppression of the immune system and damage to the nervous system depend on the types of pyrethroids and the test organisms [7]. Allethrin blocks calciu $m$ and sodium channels which underlie some of the chronic effects of low level pyrethroid poisoning [8]. Occupational exposure to fenvalerate affected the semen quality of workers of a pesticide factory [9] and it was also associated with an increase in sperm DNA damage [10].

\subsection{Mutagenicity and Carcinogenicity}

The mutagenicity of pyrethroids is considered to be very low and only permethrin has been reported as a potential or weak carcinogen by USEPA [7]. A report by WHO [11] says that no laboratory studies have revealed any carcinogenic effect relevant to humans.

\subsection{Human Exposure}

In an extensive review of 573 cases of acute pyrethroid poisoning between 1983 and 1988 in China, most 
occurred from occupational or accidental exposure. A severe form of accidental pyrethroids poisoning was reported after introduction of the insecticide into airconditioning ducts and the persons exposed suffered due to dyspnea, nausea, headache and irritability [12]. Chronic sequelae to pyrethroids exposure include cerebro-organic disorders, sensomotor-polyneuropathy in the lower extremities and vegetative nervous disorders, like paroxysmal tachycardia, increased heat sensitivity and reduced exercise tolerance related to circulatory dysfunction [13].

\section{Effects on Other Non-Target Organisms}

\subsection{Birds}

A report by Fishel [13] shows that most pyrethroids are non toxic to birds but they can be indirectly affected by pyrethroids through their food supply. Waterfowls which feed mostly on aquatic invertebrates are especially vulnerable (Table 3).

Table 3. Acute effects of py reth roids and pyreth roid formulations on non-target organisms [7]

\begin{tabular}{|c|c|c|c|}
\hline Pyrethroids & Birds (mg pyrethroids/kgbody weight) & Fish & Bees \\
\hline Allethrin & 2030 & Toxic & - \\
\hline s-Bioallethrin (Esbiol) & 680 & Highly toxic & - \\
\hline Resmethrin & - & Toxic & Highly toxic \\
\hline Bioresmethrin & - & Highly toxic & Highly toxic \\
\hline Tetramethrin & $>1000$ & Toxic & Toxic \\
\hline Permethrin & $>13500$ & Highly toxic & Highly toxic \\
\hline Fenvalerate & 9932 & Highly toxic & - \\
\hline d-Phenothrin & $>2500$ & Toxic & Toxic \\
\hline Cypermethrin & - & Extremely toxic & Toxic \\
\hline Esfenvalerate & - & Highly toxic & - \\
\hline Bifenthrin & $>2150$ & Toxic & - \\
\hline Fenpropathrin & 1089 & Toxic & - \\
\hline Refluthrin & 4190 & Highly toxic & - \\
\hline Cyfluthrin & 4450 & Toxic & Toxic \\
\hline Fluvalinate & $>5620$ & Toxic & Non-toxic \\
\hline Tralomethrin & 7716 & Extremely toxic & Highly toxic \\
\hline Delt amethrin & $>4640$ & Toxic & Highly toxic \\
\hline Cyhalothrin & $>5000$ & Highly toxic & - \\
\hline Kadethrin & - & Toxic & Toxic \\
\hline Alphacypermethrin & - & Toxic & Toxic \\
\hline Lambda-cyhalothrin & $>3950$ & Toxic & Toxic \\
\hline
\end{tabular}

In the environment pyrethroids are degraded by one or more biotic or abiotic proces ses: metabolic degradation by plants, animals and microorganisms and photodegradation.

Degradation of pyrethroids in the soil is mostly by chemical and microbial action. The rate of degradation depends on the type of pyrethroids, soil type, climate, the species of microbes present and the size of their population. The bacterial isolate Pseudomonas aeruginosa CMG 154 has been found to utilize cypermethrin as the sole source of carbon [16]. A study by Parvathavarthini [17] has evaluated the efficiency of Enterobacter asburiae and Pseudomonas stutzeri which were found to degrade cypermethrin and the degradation is high at the concentration of $500 \mathrm{ppm}$ (Table 4).

In a study by Lee et al. [18], 56 strains of SP-degrading bacteria have been isolated from contaminated sediments. They have evaluated the ability of six bacterial strains to transform bifenthrin and permethrin. Stenotrophomonas acidaminiphilia rapidly degraded bifenthrin and permethrin in the aqueous phase and reduced its half-life from $>700 \mathrm{~h}$ to 30-131h. Aeromonas sobria, Erwinia carotovora and Yersinia frederiksenii were found to degrade permethrin isomers. They reduced the half-life of cis-and trans-permethrin by approximately ten fold. Though they are said to have rapid rate of degradation in the environment, their adsorption to sediments increases their persistence by rendering them unavailable to SPdegraders which are present in the environment.

Table 4. Pyreth roid degrading bacte rial strains tested in our laboratory

\begin{tabular}{|c|c|c|}
\hline S.No & Pyrethroid & Degrading bacterial strains \\
\hline 1. & Lambda-Cyhalothrin & $\begin{array}{c}\text { Klebsiella sp. } \\
\text { Pseudomonas oleovorans }\end{array}$ \\
\hline 2. & Cypermethrin & $\begin{array}{c}\text { Enterobacter asuburiae } \\
\text { Pseudomonas stutzeri }\end{array}$ \\
\hline 3. & Fenvalerate & $\begin{array}{c}\text { Bacillus cereus } \\
\text { Pseudomonas viridiflava }\end{array}$ \\
\hline
\end{tabular}

Bacillus cereus, Pseudomonas fluorescens and Achromobacter spp. were able to degrade permethrin, deltamethrin, fastac, fenvalerate and fluvalinate. Permethrin was the most rapidly degraded of the pyrethroids and deltamethrin was reported to be the most persistent (half-life of 21-28 days) [19]. P. fluorescens and Serratia plymuthica isolated from SP-contaminated farmland surrounding a sheep dipping facility and garden soil was observed to degrade SPs by at least $50 \%$ after twenty days of treatment. It was found to be greater than the natural breakdown which suggests biodegradation as a practical and appropriate solution for detoxifying SPs whether in dip trough, river or soil before they are disposed [20]. 


\section{Conclusion}

The growing population has increased the demand for food supply which in turn has increased the usage of insecticides and pesticides to protect the precious food source. This indiscriminate usage of pyrethroids has led to severe pollution which should be checked. New analytical techniques have to be developed to detect pyrethroids in the aquatic systems. Biodegradation is a practical approach to reduce pyrethroid toxicity in the environment and other approaches like the application of esterases to reduce pyrethroids toxicity can be seriously considered.

\section{Acknowledgments}

The authors thank the authorities of The American College, Madurai for encouragement.

\section{References}

[1] Schmitt, C.J. Environmental Contaminants. US Geological Survey. $2005,100 \mathrm{pp}$.

[2] Agency for Toxic Substances and Disease Registry. Toxicological Profile for Pyrethrins and Pyrethroids. US Department of Health and Human Services, 2003, 238pp.

[3] Gan, J., Lee, S.J., Liu, W.P., Haver, D.L. and Kabashima, J.N . Distribution and Persistence of Pyrethroids in Runoff sediments. $J$ Environ Qual 34:836-841.2005.

[4] Amweg, E.L., Weston, D.P. and Ureda, N.M . Use and Toxicity of Pyrethroid Pesticides in the Central Valley, California, USA. Environmental Toxicology and Chemistry 24: 966-972. 2005.

[5] Beenakumari, Madan, V.K. and Kathpal, T.S.. Pesticide residues in rainwater from Hisar, India. Environ Monit Assess 133:467471.2007.

[6] Khambay, B.P.S. Pyrethroid insecticides. The Royal Society of Chemistry.2002.

[7] Mueller-Beilsehmidt, D. Toxicology and Environmental fate of synthetic pyrethroids. Jouma of Pesticide Reform 10-I: 17pp, 1990.

[8] Hildebrand, M.E., McRory, J.E., Snutch T.P. and Stea, A. Mammalian Voltage-Gated calcium channels are potently blocked by the pyrethroids insecticide Allethrin. The Journal of Pharmacology and Experimental Therapeutics 308: 805-813.2004.

[9] Lifeng, T., Shoulin, W., Junmin, J., Xuezhao, S., Yannan, L. Qianli, W and Longsheng, C. Effects of Fenvalerate exposure on semen quality among occupational workers. Contraception 73:9296. 2006.

[10] Bian, Q., Xu, L.C., Wang, S.L., Xia, Y.K., Tan, L.F., Chen, J.F., Song, L., Chang, H.C and Wang, X.R. Study on the relation between occupational Fenvalerate exposure and Spermatozoa DNA damage of pesticide factory workers. Occupational and Environmental Medicine 61: 999-1005. 2004.

[11] Safety of Pyrethroids for public health use. World Health Organizat ion. 2005. 77pp.

[12] Chen S.Y., Zhang Z.W., He F.S., An epidemiological study on occupational acute pyrethroids poisoning in cotton farmers. $\mathrm{Br} \mathrm{J}$ Ind Med 48:77-81. 1991.

[13] Muller-Mohnssen H. Chronic sequelae and irreversible injuries following acute pyrethroids intoxication. Toxicol Lett 107:161-76. 1999.

[14] Fishel, F.M. Pesticide toxicity profile: Synthetic Pyrethroid pesticides, University of Florida, Institute of Food and Agricultural Sciences. 2005.

[15] Saha, S and Kaviraj, A. Acute toxicity of synthetic pyrethroid Cypermethrin to some freshwater organisms. Bull. Environ. Contam.Toxicol.80: 49-52. 2008.

[16] WHO. Chemical watch factsheet: Synthetic pyrethroids. World Health Organisation. 1995.

[17] Qureshi, F.M., Akhtar, J., Badar, U., Fasim, F., Jameel, N., Raihan, S., Hassan, M and Ahmd, N. Towards effect ive bioremediat ion in Third World Counries. The Association of Environmental Health and Sciences. 2001.

[18] Parvathavarthini, R. Biodegradation of Cypermethrin by Enterobacter asburiae, Post Graduate dissertation submitted to The American College, Madurai, India, 2006. 39pp.

[19] Lee, S., Gan, J., Kim, J., Kabashima, J.N., Crowley, D.E. Microbial transformation of pyrethroid insecticides in aqueous and sediment phases. Environmental Toxicology and Chemistry 23: 16. 2003.

[20] Maloney, S.E., Maule, A and Smith, A.R.W. Microbial transformation of the pyrethroids pesticide insecticides: Permethrin, Deltamethrin, Fastac, Fenvalerate and Fluvalinate. Applied and Environmental Microbiology 54:2874-2876. 1988.

[21] Grant, R.J., Daniell, T.J. and Betts, W.B. Isolation and identification of synthetic pyrethorid-degrading bacteria. Journal of Applied Microbiology 92:534-540. 2002. 